\title{
Article \\ Complex Thinking in the Framework of Education 4.0 and Open Innovation-A Systematic Literature Review
}

\author{
María Soledad Ramírez-Montoya ${ }^{1, *}$, Isolda Margarita Castillo-Martínez ${ }^{2}$, Jorge Sanabria-Z ${ }^{1}$ (1) \\ and Jhonattan Miranda ${ }^{3}$ \\ 1 Institute for the Future of Education, Tecnologico de Monterrey, Monterrey 64700, Mexico; \\ jorge.sanabria@tec.mx \\ 2 School of Humanities and Education, Tecnologico de Monterrey, Monterrey 64700, Mexico; \\ isoldamcm@hotmail.com \\ 3 School of Engineering and Sciences, Tecnologico de Monterrey, Mexico City 14380, Mexico; \\ jhonattan.miranda@tec.mx \\ * Correspondence: solramirez@tec.mx
}

check for

updates

Citation: Ramírez-Montoya, M.S.; Castillo-Martínez, I.M.; Sanabria-Z, J.;

Miranda, J. Complex Thinking in the

Framework of Education 4.0 and

Open Innovation-A Systematic

Literature Review. J. Open Innov.

Technol. Mark. Complex. 2022, 8, 4 .

https://doi.org/10.3390/

joitmc8010004

Received: 7 October 2021

Accepted: 28 November 2021

Published: 4 January 2022

Publisher's Note: MDPI stays neutral with regard to jurisdictional claims in published maps and institutional affiliations.

Copyright: (c) 2022 by the authors. Licensee MDPI, Basel, Switzerland. This article is an open access article distributed under the terms and conditions of the Creative Commons Attribution (CC BY) license (https:// creativecommons.org/licenses/by/ $4.0 /)$

\begin{abstract}
Today's complex, dynamic, interconnected world presents the field of education ("Education $4.0^{\prime \prime}$ ) with significant challenges in developing competencies for reasoning for complexity. This article analyzes complex thinking as a macro-competency with sub-competencies of critical, systemic, scientific, and innovative thinking in educational environments. We worked with the systematic literature review method, selecting 35 articles in the Scopus and Web of Science databases using keywords words of interest and applying inclusion and exclusion criteria. Seven research questions guided the data analysis. The results highlighted that: (a) there are common characteristics of studies linking complex thinking, critical thinking, and creative thinking; (b) there is predominance of the qualitative method in the studies; (c) the critical thinking competency has been the most addressed in the research; (d) the predominant components of Education 4.0 are teaching methods and techniques; and (e) the three challenges that stand out for educational research are project feasibility, research opportunities, and required skills. This article is intended to be of value to academic and social communities and decision-makers interested in developing reasoning for complexity within the framework of Education 4.0.
\end{abstract}

Keywords: complex thinking; reasoning for complexity; educational innovation; Education 4.0; higher education; open innovation

\section{Introduction}

In a continuously changing and challenging world, complexity predominates in the new perspectives that are demanded. The complexity paradigm is discussed by Morin [1], who proposes that complex thinking that addresses the "interwoven" from a dialogical point of view, which implies considering the separate and sometimes contradictory interacting parts that compose the phenomenon in a specific context. In addition, the author mentions that recursive thinking must be mobilized, i.e., a way of thinking to establish a dynamic and generative feedback loop between terms or concepts (for example, whole and part, order and disorder, observer and observed, system and ecosystem) that are both complementary and antagonistic [2]. If the problem of knowledge (and knowledge of knowledge) is posed, it is necessary to realize that the task is not individual; it would require the encounter and the exchange between all researchers and academicians working in disjunct domains [3]. In particular, training in complex reasoning is a necessity for academic communities. Thus, new technology-based teaching-learning systems have emerged to respond to the complex changes and social challenges through higher education. The use and adaptation of these technologies in the current context of society is known today as Education $4.0[4,5]$. 
This article aims to analyze complex thinking as an emerging area within the framework of Education 4.0. Other literature reviews have contributed to the field of education. For example, in primary education, work has been performed on language issues using digital games [6], argumentation [7], and signs and symbols [8]; also, in higher education, Francisco et al. [9] and Landa [10] have analyzed in their studies the pedagogy of questioning and the politics of language respectively. This article contributes to the rarely explored area of reasoning for complexity linked to Education 4.0. The fields of reasoning for complexity and research are presented, followed by an examination of Education 4.0. The systematic literature review method presented has five protocol phases. This discussion is followed by the results and data analyses and concludes with the findings and the study's limitations. The article aims to be of value to research groups, academicians, and society interested in opportunities for training in reasoning competencies for complexity within the framework of Education 4.0.

\subsection{Reasoning for Complexity and Research}

Higher education training requires the integration of complex thinking to support educational processes for the formation of citizens committed to society. Hays [11] warns against conventional higher education that does not sufficiently prepare young professionals for the complicated demands of modern business or active participation in their communities. In the same vein, Jörg et al. [12] indicate a need to develop a theory of complexity, a new paradigm for education that can capture the complex processes of learning, rethinking modes of inquiry, using a new lexicon, and assessment practices for the complexity paradigm. In this sense, what does training for complexity imply? Tecnologico de Monterrey [13] outlines the transversal competency of reasoning for complexity in terms of meta-competence that involves integrative thinking, enabling analysis, synthesis, problem-solving, and continuous learning. It implies mastering the cognitive skills necessary for scientific, critical, and systemic thinking to meet the contextual challenges demanded of them to exercise their profession and commit as citizens to the transformation of the environment.

Undoubtedly, the educational field is experiencing these challenges with uncertainty and vulnerability, and training to develop the meta-competence of reasoning for complexity is especially challenging for education. Four sub-competencies can be identified: critical, systemic, scientific, and innovative thinking [14]. Critical thinking is the intellectually disciplined process of actively and skillfully conceptualizing, applying, analyzing, synthesizing, and evaluating information acquired or generated by observation, experience, reflection, reasoning, or communication as a guide to belief and action [15]. Systemic thinking is the underlying reasoning that students must develop to analyze and understand complex global systems and phenomena [16]. Ref. [17] describes innovative thinking as the capacity for creativity, implemented with a high degree of success; they delineate four levels: "incremental" innovation, "modular" innovation, "architectural" innovation, and "radical" innovation. Scientific thinking is higher-order thinking that helps students face the era of global competition to overcome various problems. It involves logical, analytical, systematic, inductive, and deductive thinking to solve problems. It includes defining, identifying, and formulating alternative proposals and determining the best solutions [18]. These processes need to be analyzed through educational research.

Educational research involves applying the scientific method in educational processes. Harwell [19] outlines different research methods: (a) qualitative research methods (narratives, phenomenological studies, grounded theory, ethnographies, case studies); (b) quantitative research methods (experimental design, quasi-experimental designs, pre-experimental, ex-post-facto: transactional designs; ex-post-facto: longitudinal designs); and (c) mixed methods (sequential explanatory design, sequential exploratory design, sequential transformative design, concurrent triangulation design, concurrent nested design). Some challenges in developing research competencies have been detected by Castillo-Martínez and Ramírez-Montoya [20]: research opportunities, feasibility, 
knowledge-sharing, collaboration, and skills differences. Scientific evidence of research in the field of complexity and innovation is provided by Sun [21], who integrated the concept of sustainable design into a first-year engineering entry course that emphasized creative thinking and innovation through an open team project to enhance innovative thinking, communication, and teamwork skills. Similarly, to assess innovative thinking in adults with attention-deficit/hyperactivity disorder (ADHD), White and Shah [22] used a realistic word association task and investigated a possible cognitive mechanism for ADHD-related advantages in innovative thinking. The results support the possibility that ADHD is positively associated with specific aspects of innovative thinking, which may be attributed in part to a broad scope of semantic activation.

\subsection{Framework of Education 4.0}

Today, the technological advancement of humanity has resulted in new technologies that provide high capacities and performance capabilities in new systems, platforms, devices, and artifacts [23]. Thus, various product and service sectors have competitive advantages to achieve high levels of efficiency in their processes and generate better use of their resources [24]. Thanks to this advance, technologies for connectivity, "smartification," digitalization, virtualization, and datafication have emerged, which today are characteristic technologies of the fourth industrial revolution (Industry 4.0), also known as Technologies 4.0. One of the service sectors most evolved thanks to this technological advance is higher education.

According to Miranda et al. [5], Education 4.0 means "seeking to graduate a new generation of highly competitive professionals capable of applying the right physical and digital resources to provide innovative solutions to current and future societal challenges." Other authors mention that Education 4.0 enables the resources to train and develop competencies and skills for Industry 4.0 [25]. Moreover, the Education 4.0 concept has been applied to generating and implementing innovative practices in education. In this context, educational innovation seeks "best practices" of active learning, relying primarily on technological components for its implementation [26].

In addition, Education 4.0 can be viewed from a philosophical point of view. In the evolution of the education sector from Education 1.0 (late 18th century), Education 2.0 (early 20th century), and Education 3.0 (late 20th century) to Education 4.0 (present), education has transcended from essentialism, behaviorism, instructivism, and andragogy towards an approach based on "cybergogy"; the latter combines educational experience with the use of ICTs, "peeragogy" which encourages cooperation and collaboration in educational processes, and "heutagogy" which is based on humanist and constructivist principles to foster self-learning practices [5]. Therefore, taking these approaches as a reference, we can say that Education 4.0 promotes (i) transition from teacher-centered to student-centered instruction and from passive to active learning [27], (ii) looks for real-life contexts, scenarios, and challenges where the students strengthen their professional training by putting their knowledge into practice, and (iii) develop research and complex thinking skills to propose solutions to current challenges and problems in society [14].

In this article, the authors propose a framework based on the five core components of Education 4.0 that enable designing innovative pedagogical procedures to carry out best practices and dynamics with correct technologies and infrastructure (see Figure 1):

1. Competencies. Training and developing desirable transversal and disciplinary competencies in today's students.

2. Teaching-Learning Methods. Incorporating new active learning methods and modalities (face-to-face learning, hybrid learning, and distance learning).

3. Stakeholders. Inducing active participation and collaboration among key stakeholders, applying open-strategy methods, and triple and quadruple helix models.

4. Technologies 4.0. Using current and emerging ICT for connectivity, virtualization, digitalization, datafication, and "smartification." 
5. Infrastructure. Accessing innovative infrastructure (services, platforms, facilities) at the institutional, classroom, and home levels.

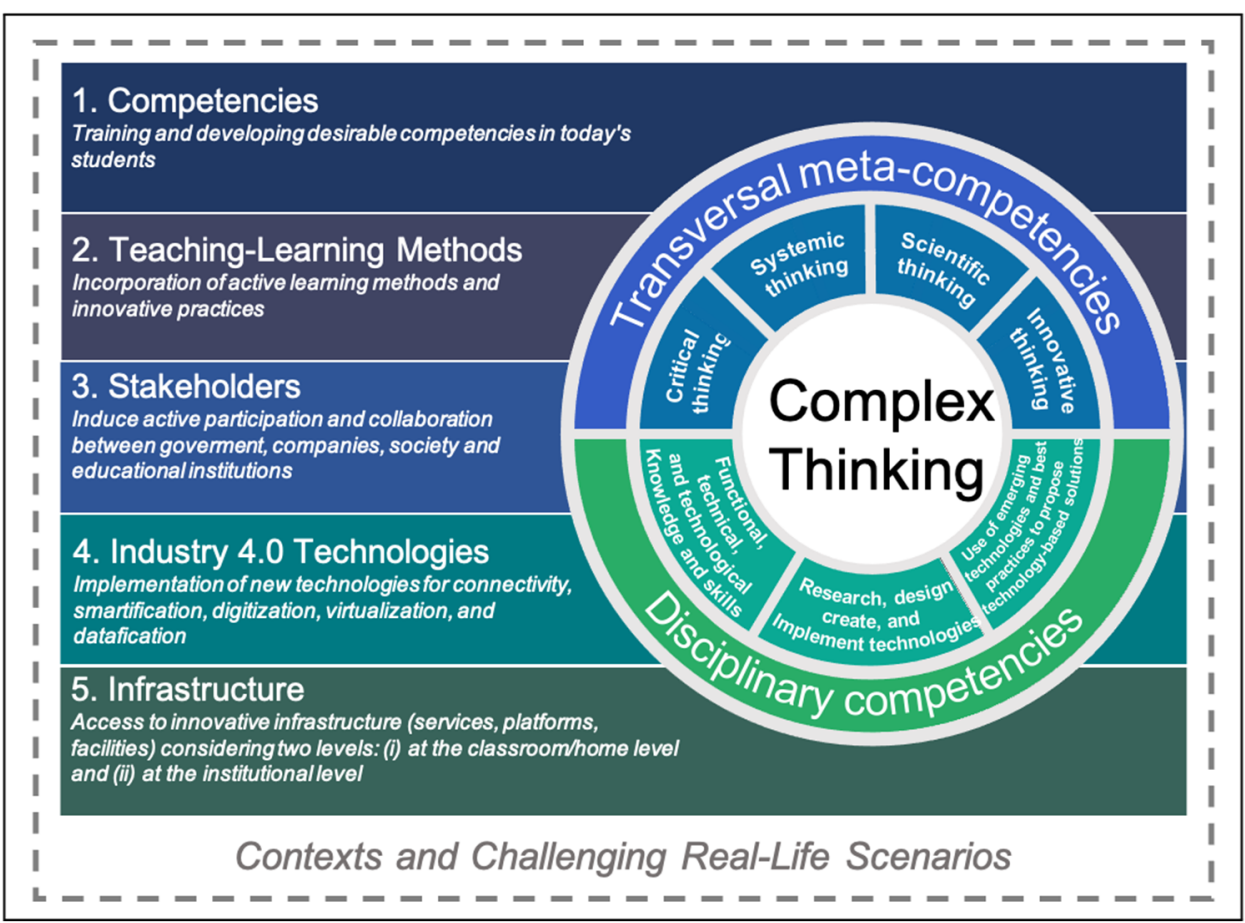

Figure 1. Complex thinking in Education 4.0.

\section{Materials and Methods}

The systematic literature review was the method for analyzing the articles. Kitchenham and Charters [28] state that the systematic literature review supports the evaluation and interpretation of thematic areas. Based on the guidelines of the University of York [29] and Verner et al. [30], we used a protocol that included: (1) research questions; (2) search process; (3) inclusion and exclusion criteria; (4) data selection and extraction process, and (5) data synthesis.

\subsection{Research Questions}

In order to analyze the characteristics of complex thinking studies, seven research questions were posed, as shown in Table 1.

Table 1. Themes and research questions (RQ).

\begin{tabular}{|c|c|c|}
\hline Themes & Research Questions (RQ) & Possible Answers Based on Literature \\
\hline \multirow{5}{*}{$\begin{array}{c}\text { General characteristics of complex } \\
\text { thinking studies }\end{array}$} & $\begin{array}{l}\text { RQ1. How are the keywords of the } \\
\text { studies related? }\end{array}$ & Co-Terms Network \\
\hline & \multirow{2}{*}{$\begin{array}{l}\text { RQ2. In which years were the articles } \\
\text { published, and in which journals and } \\
\text { quartile levels? }\end{array}$} & Year of publication \\
\hline & & $\mathrm{Q}$ of the journal \\
\hline & \multirow{2}{*}{$\begin{array}{l}\text { RQ3. In which journals have the most } \\
\text { cited articles been published? }\end{array}$} & Articles with more citations \\
\hline & & Journals with more publications \\
\hline Methodological strategies & $\begin{array}{l}\text { RQ4. What methods were used in the } \\
\text { articles? }\end{array}$ & $\begin{array}{l}\text { Methods [19]: } \\
\text { Quantitative methods } \\
\text { Qualitative methods } \\
\text { Mixed methods }\end{array}$ \\
\hline
\end{tabular}


Table 1. Cont.

\begin{tabular}{|c|c|c|}
\hline Themes & Research Questions (RQ) & Possible Answers Based on Literature \\
\hline Types of reasoning for complexity & $\begin{array}{l}\text { RQ5. What kind of complex thinking is } \\
\text { reflected in the studies? }\end{array}$ & $\begin{array}{l}\text { Kind of complex thinking [14] } \\
\text { Systemic thinking } \\
\text { Scientific thinking } \\
\text { Critical thinking } \\
\text { Innovative thinking }\end{array}$ \\
\hline Complex thinking in Education 4.0 & $\begin{array}{l}\text { RQ6. Which Education } 4.0 \text { component is } \\
\text { predominant in the articles? }\end{array}$ & $\begin{array}{l}\text { Education } 4.0 \text { components [26]: } \\
\text { Competencies } \\
\text { Teaching and learning methods } \\
\text { Technologies } 4.0 \\
\text { Infrastructure } \\
\text { Stakeholders }\end{array}$ \\
\hline Challenges for educational research & $\begin{array}{l}\text { RQ7. What are the educational research } \\
\text { challenges identified in the studies? }\end{array}$ & $\begin{array}{c}\text { Research challenges [20]: } \\
\text { Research opportunities } \\
\text { Feasibility } \\
\text { Knowledge sharing } \\
\text { Collaboration } \\
\text { Skills differences }\end{array}$ \\
\hline
\end{tabular}

\subsection{Search Process}

The article search protocol utilized the electronic features in the Scopus and Web of Science (WoS) databases. We delimited the keywords (reasoning for complexity and four types of thinking: innovative, critical, scientific, and systemic). The search strings are presented in Table 2.

Table 2. Search strings used in the indexing systems.

\begin{tabular}{cc}
\hline Scopus & Web of Science (WoS) \\
\hline TITLE-ABS-KEY ("complex thinking" AND & TOPIC: ("complex thinking") AND TOPIC: \\
("critical thinking" OR "innovative thinking" & ("critical thinking" OR "innovative thinking” \\
OR “systemic thinking" OR “scientific & OR "systemic thinking" OR \\
thinking")) AND (LIMIT-TO (DOCTYPE, “ar") & "scientific thinking") \\
OR LIMIT-TO (DOCTYPE, "cp") OR LIMIT-TO & Timespan: All years. Indexes: SCI-EXPANDED, \\
(DOCTYPE, "ch") OR LIMIT-TO & SSCI, A\&HCI, CPCI-S, CPCI-SSH, BKCI-S, \\
(DOCTYPE, "re")) & BKCI-SSH. \\
\hline
\end{tabular}

\subsection{Inclusion and Exclusion Criteria}

The field of reasoning for complexity can be approached in multiple ways. In this case, we focused on education as a meta-competency and selected four sub-competencies. The inclusion criteria stipulated that they must be articles that included "reasoning for complexity" in their title, abstract, or keywords. These words were used only as basic search terms, without determining whether the articles intentionally and/or directly addressed the concept as an issue. Exclusion terms (non-exhaustive) were other topics that did not delineate the four sub-competencies.

\subsection{Data Selection and Extraction Process}

The search resulted in identifying 28 articles in Scopus and 20 in WoS. The articles were reviewed in both databases to eliminate possible duplicates. We found eight duplicates and removed them from the Scopus listing. In the end, 35 articles were selected. They can be consulted in the integrated Excel file. The following data were previously extracted from the identified studies: authors, title, doi, abstract, country, and keywords. The researchers used a data extraction form tied explicitly to the seven research questions in the SLR. A peer-review validation was performed to check the identification of the responses; in case of discrepancies, agreements were made for selecting the responses to achieve $100 \%$ data 
verification. Figure 2 outlines the delimitation of articles for the systematic literature review using the Prisma method [31].
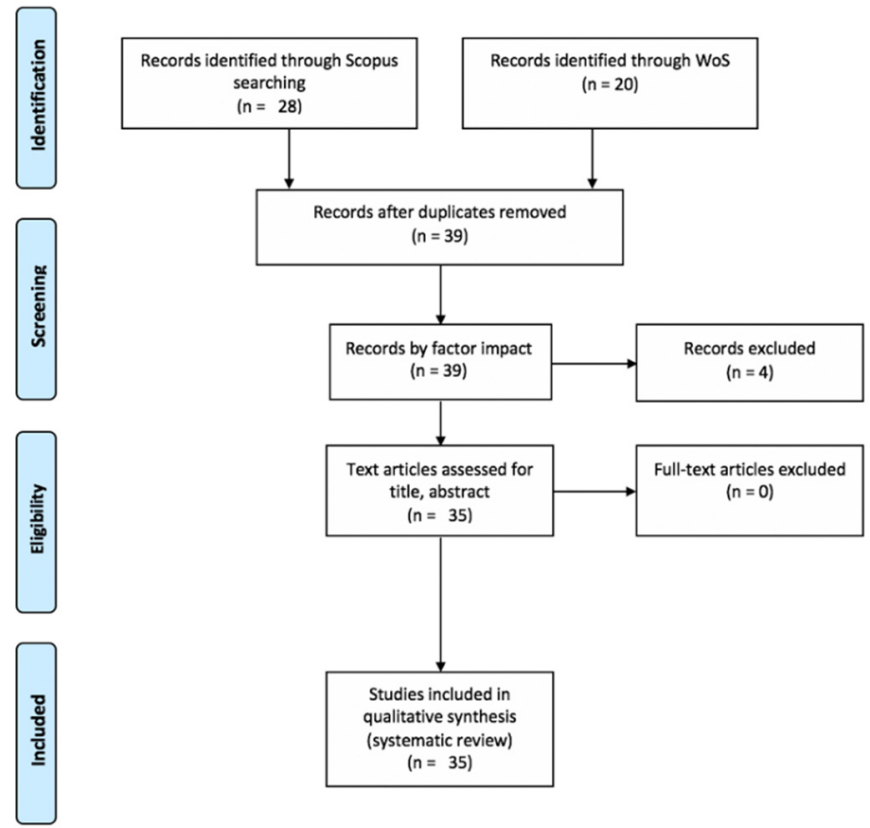

Figure 2. Prisma flow diagram for SLR [31].

\subsection{Data Synthesis}

The information analysis to find answers to the research questions was supported by a theoretical framework to identify guiding elements in the articles. Content analysis was the qualitative technique, objectively making inferences from a focal text in a social context [32], based on one mechanical and one interpretative component [33]. The first involved organizing the data into the study themes, and the second was determining the meaningful data in terms of the research questions [34]. We also worked with source triangulation [35], in which the data were validated in a peer review [36]. The answers were synthesized with a prior classification that would lead to possible graphic representations. Analyses were carried out to locate interesting intersections of terms, keywords, networks of co-terms, categories, and subcategories. The data of the analyses are presented in this integrated excel sheet: https:/ /hdl.handle.net/11285/638752 (accessed on 13 September 2021). Identifying numbers for each item are identified by ID in the references document: https:/ / doi.org/10.5281/zenodo.5746250 (accessed on 30 November 2021).

\section{Results}

This section presents the results tied to the research questions. The tools used for the graphs were VOSviewer and Tableau.

$R Q 1$. How are the keywords of the studies related?

The analysis of the studies considered the keywords of the articles analyzed, shown in Figure 3. Three terms stand out with correlation: complex thinking, critical thinking, and creative thinking. 


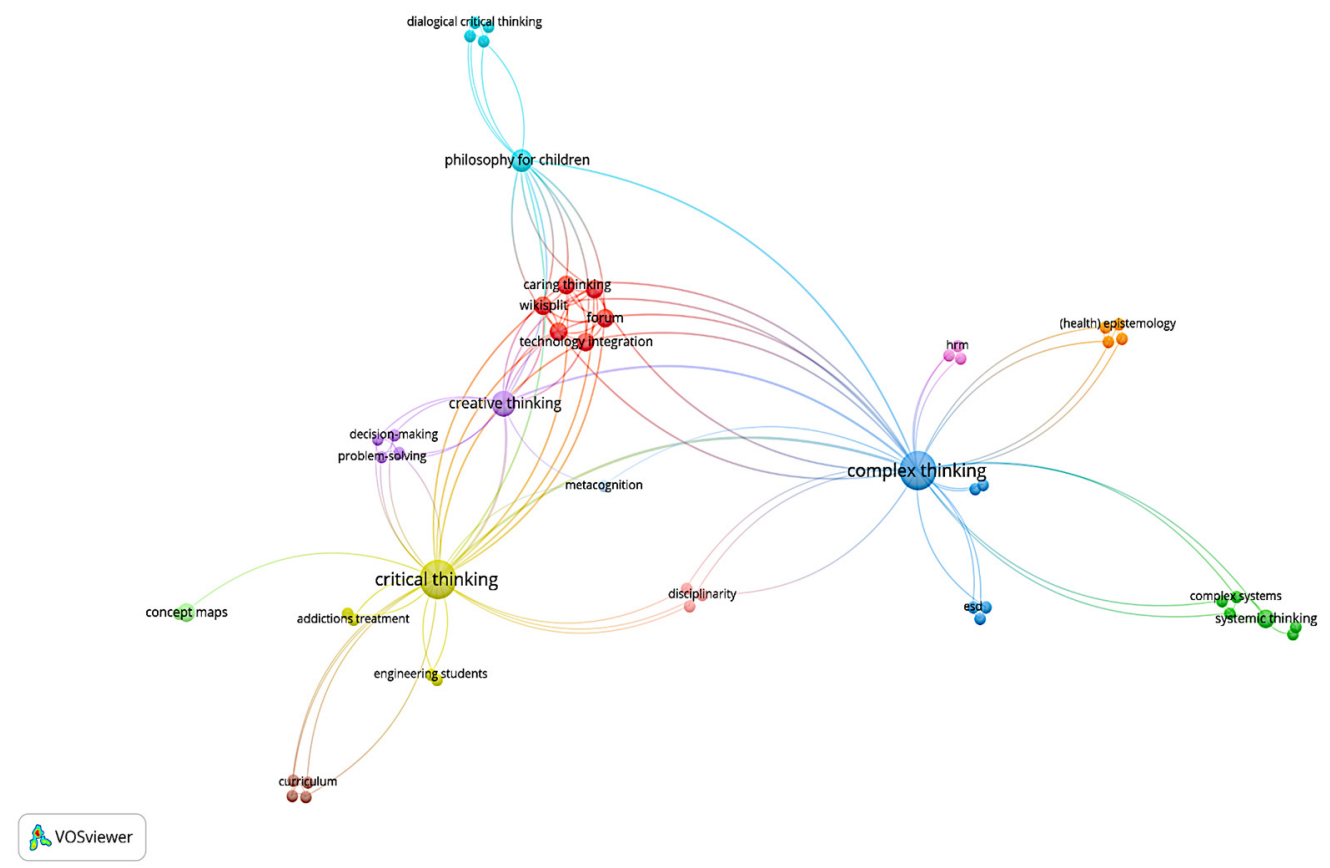

Figure 3. Keywords of the studies and connection nodes.

The articles' keywords that appeared most frequently were complex thinking and critical thinking, followed by creative thinking. One of the studies even implemented a complex thinking model that utilized cognitive tools such as the use of spreadsheets, which allowed identifying that there was a large contribution to critical thinking skills, although there was a slight contribution to creative thinking skills. Another research presented framework models aimed at developing, stimulating, and engaging students' complex thinking process skills and conceived the following as subcompetencies of this type of thinking: problem solving, critical thinking, creative thinking, and decision making. There are also keywords related to cognition, such as cognitive critical thinking, cognitive tool, cognitive skills, and metacognition.

$R Q 2$. In which years were the articles published, and in which journals and quartile levels?

We analyzed the years of publication, journals, and the quartiles corresponding to the journals in which the papers were published, as shown in Figure 4.

The papers analyzed were published from 2002 to 2021. The highest number of papers was published in 2019 (5) (ID: 2, 3, 8, 13, and 33), followed by four papers (ID: 17, 20, $22,25)$ in 2021. There were two papers published on the study topic in the years 2004 (ID: 14,21), 2012 (ID: 5,32), 2013 (ID: 4,10) 2015 (ID: 29,31), 2017 (ID: 23,24), 2018 (ID: 6,12), and 2020 (ID: 11,26). Only one paper was published on the topic in the years 2002 (ID: 7), 2006 (ID: 15), 2008 (ID: 1), 2009 (ID: 34), and 2011(ID: 18). There were no publications in 2003, 2005, 2007, and 2010. Regarding the quartiles in which the papers belonged, the highest number of papers corresponded to Q4 with eight papers, followed by Q1 with seven papers. Q3 had three papers, and Q2 had one. The analysis also identified twelve conference papers and four book chapters. 


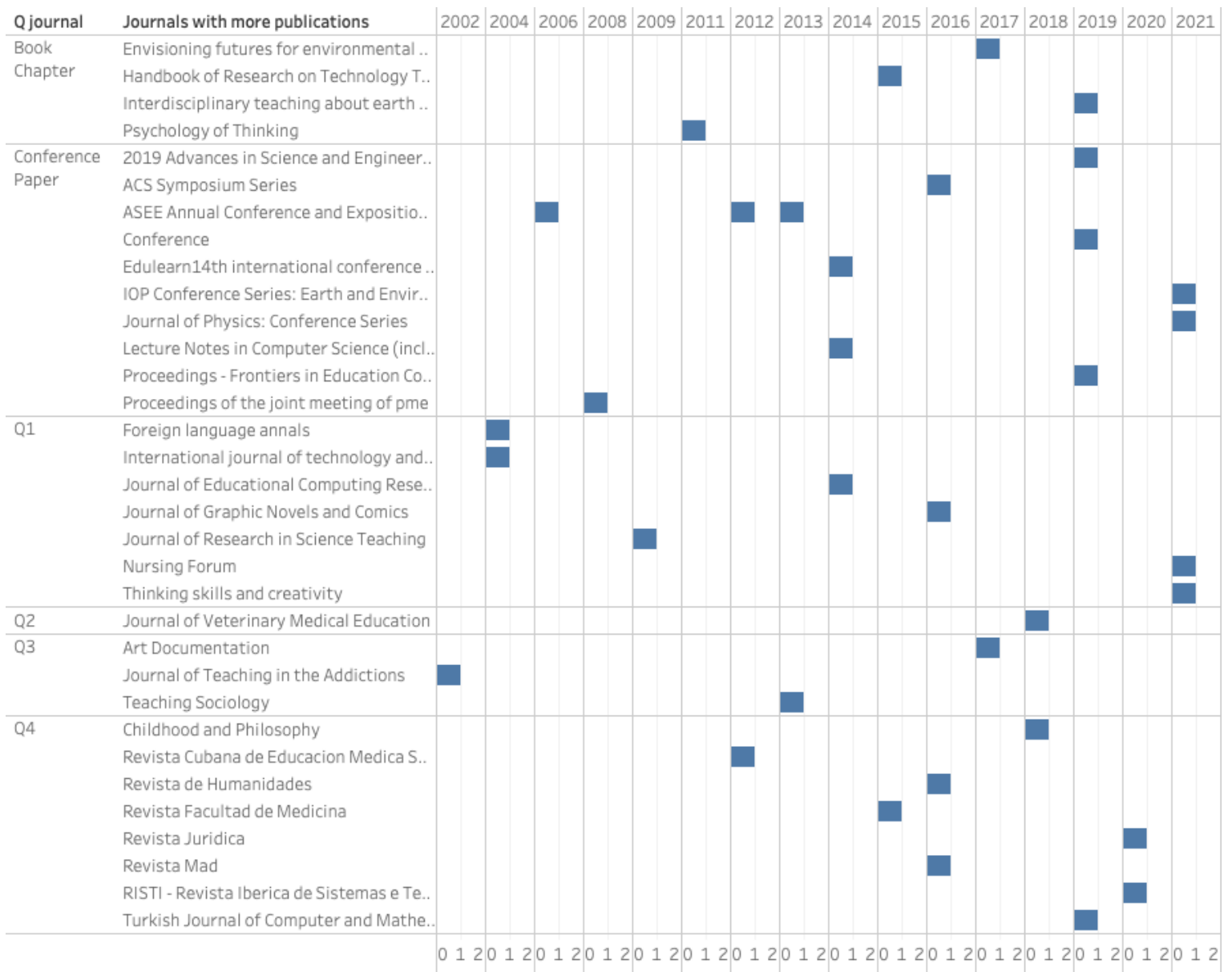

Figure 4. Years, journals, and quartiles of analyzed papers.

Furthermore, Figure 4 shows that so far, the year with the most publications related to the complexity reasoning competency is 2019 , followed by 2021, 2016, and 2014. As an example, the findings found in publications during that period are provided. In the work of Dere et al. (2019) a new conceptualization for complex thinking is proposed through a process of synthesis and conjugation of different conceptual perspectives. In the research of Hidayati et al. (2021), research results show that constructivism-based mathematics learning tools for eleventh graders of SMA N 2 Lubuk Basung can be declared valid. Harbi's (2016) study suggests that comics can be a suitable medium for educating critical thinking and introducing complex and abstract concepts to children. In addition, Rosen and Mosharraf's (2014) study aimed to explore students' critical thinking performance and motivation patterns in the Evidence-Centered Concept Map (ECM) mode compared to the basic notepad mode.

RQ3. In which journals have the most cited articles been published?

It was important for the study to know which journals had the most publications related to the complex reasoning competency and the articles with the highest number of citations. This information is shown in Table 3. 
Table 3. Journals and citations of the analyzed papers.

\begin{tabular}{cccc}
\hline Journal Name & Q Journal & ID Articles & Citations \\
\hline Journal of Research in Science Teaching & Q1 & 34 & 119 \\
\hline Foreign Language Annals & Q1 & 14 & 58 \\
\hline Journal of Educational Computing Research & Q1 & 30 & 25 \\
\hline Teaching Sociology & Q3 & 10 & 9 \\
\hline Revista Cubana de Educación Médica Superior & Q4 & 5 & 7 \\
\hline Journal of Veterinary Medical Education & Q2 & 6 & 4 \\
\hline Revista Facultad de Medicina & Q4 & 31 & 4 \\
\hline
\end{tabular}

Table 3 shows that the paper with the highest number of citations (119) appeared in the Journal of Research in Science Teaching. The paper is titled, "How and when does complex reasoning occur? Empirically driven development of a learning progression focused on complex reasoning about biodiversity." In second place was the paper "Literary discussions and advanced speaking functions: Researching the (dis)connection," which had 58 citations in the journal Foreign Language Annals. The paper "Making student thinking visible through a concept map in computer-based assessment of critical thinking" had 25 citations and appeared in the Journal of Educational Computing Research. These were followed by papers with fewer citations, between two and nine, namely: "A Framework for Implementing Higher-Order Thinking Skills (Problem-Solving, Critical Thinking, Creative Thinking, and Decision-Making) in Engineering Humanities", " Defining and measuring innovative thinking among engineering undergraduates", "Learning plus service as a methodology for the development of critical thinking in higher education", "Developing a professional studies curriculum to support veterinary professional identity formation"," From von Bertalanffy to Luhmann: Deconstruction of the concept 'Agroecosystem' through systemic generations", "Creating a Culture of Good Writing: A Cumulative Model for Teaching Writing in the Sociology Major", "Critical thinking skills of engineering students: Undergraduate vs. Graduate students", "Learning to teach the cognitive skills and emotional dispositions required in the 21st century", "Visual thinking strategies from the museum to the library: Using VTS and art in information literacy instruction", " Course-Embedded Undergraduate Research Experiences: The Power of Strategic Course Design"," Education to listening laboratories: experiences of reflective laboratories in university curricula", and "Mental health in the time of war, a reflection about the relationship between the armed conflict and the mental health in the Emberá indigenous people under situation of forced displacement".

RQ4. What methods have been used in the articles? And RQ5: What kind of thinking is reflected in the studies?

It is valuable to know which methods have been chosen by researchers to carry out studies related to the reasoning for complexity to identify niches concerning research approaches that have not been sufficiently utilized. It is also helpful to identify which types of thinking are addressed in the articles studied to identify whether further studies are needed that address the complex reasoning competency as a whole and not just specific sub-competencies (Figure 5). 


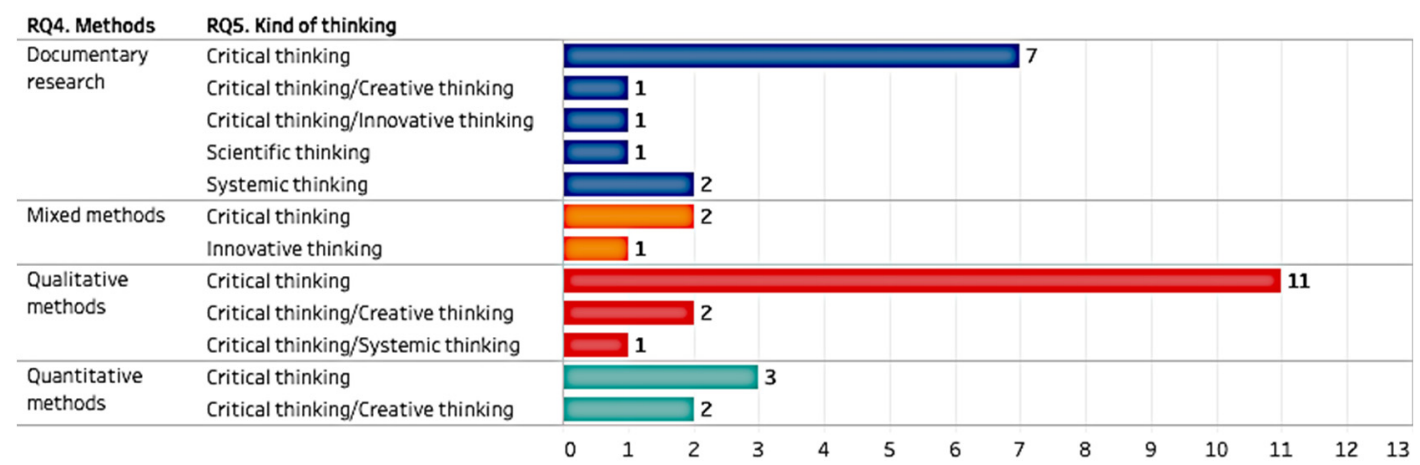

Figure 5. Methods and kind of thinking reflected in the papers.

Figure 5 shows a predominance in the use of qualitative methods (14 papers, ID: 12, $13,14,15,17,19,21,23,24,28,29,30,31$, and 35), followed by documentary research (12 papers, ID: 5, 6, 7, 8, 9, 11, 16, 18, 22, 25, 26, and 27) and a lesser use of quantitative methods and mixed methods (5 papers, ID: 2, 3, 32, 33, 34, and 4 papers, ID: 1, 4, 10, and 20, respectively). There is a considerable predominance of the reflection of critical thinking in the studies (31 papers, including those that share with other types of thinking, ID: 1, $2,3,5,6,7,8,10,12,13,14,15,16,17,18,19,20,21,22,23,24,25,26,28,29,30,31,32$, $33,34,35)$, especially those with a qualitative approach and documentary research. The types of thinking that form part of the reasoning for complexity competency also appear, although to a lesser extent: creative thinking, innovative thinking, scientific thinking, and systemic thinking.

One of the studies that used the qualitative method, through grounded theory, conducted research to ultimately generate a rigorous and meaningful assessment tool that contributes to the evaluation and understanding of children's cognitive processes who benefit from philosophical praxis which positively influences their critical thinking. On the other hand, quantitatively focused research sought to focus on learning progressions as one of the efforts to provide more coherent science curriculum sequences and assessments that can focus on complex thinking about core science topics, under the premise that to compete in a global economy, students will need resources and curricula focused on critical thinking and reasoning in science. Another study using mixed methods examined the relationships between critical thinking education and mathematics education by examining the teaching and learning of critical thinking according to the infusion approach, which combines critical thinking and mathematical content. The results of one of the documentary research projects dealt with the conceptualization of service learning and critical thinking in higher education, their interrelation, and models of service learning implementation.

RQ6. Which Education 4.0 component is predominant in the articles? And RQ7: What are the educational research challenges identified in the studies?

The main components of Education 4.0 are beneficial because they represent a trend in education, not just in industry. The content of the articles was analysed in order to identify which of the components of Education 4.0 were emphasised the most, and thus those that referred to the development of transversal or disciplinary competencies in students were classified as "Competencies". In the case of articles that focused on strategies or models, they were classified as "Teaching-learning methods", whereas if they focused on participation and collaboration of the subjects, they were classified as "stakeholder". Those articles that emphasised the use of information and communication technologies such as virtualisation, smartification, and data science, were classified as "Technologies 4.0" and lastly, those that focused on services and platforms, were classified as "Infrastructure", whether in institutions, classrooms, or homes. Moreover, the findings reveal the areas of opportunity for research on the reasoning for complexity competency (Figure 6). 


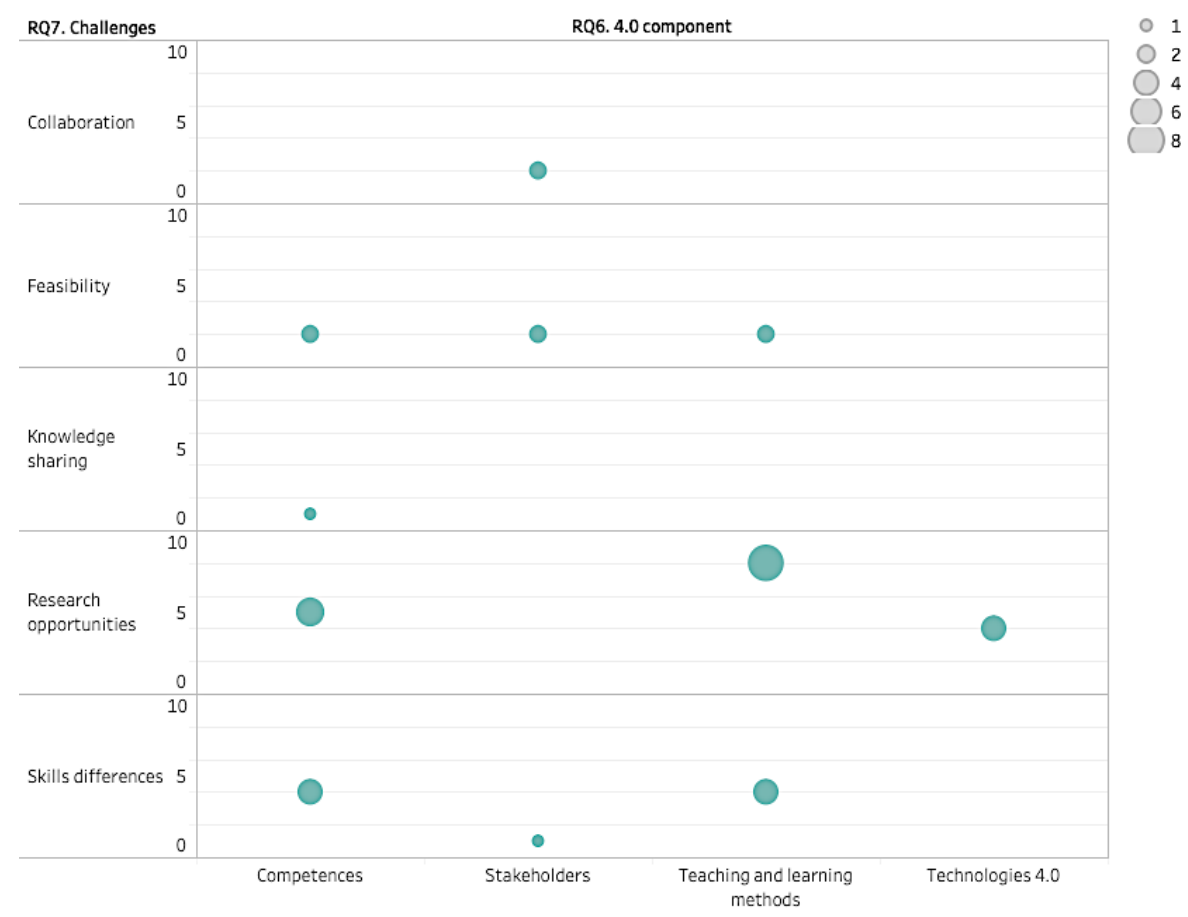

Figure 6. Predominant components and educational research challenges in the papers.

Figure 6 shows that the main component refers to teaching and learning methods in different areas such as engineering, mathematics, technology, and education (ID: 2, $3,4,6,7,18,19,20,21,23,24,28,33$, and 34). In second place are competencies in mathematics, epidemiology, philosophy, geoscience, literature, engineering, education, and transdisciplinarity (ID: 1, 8, 10, 12, 13, 14, 15, 16, 17, 22, and 27). Concerning the findings, the three that stand out are the project feasibility (ID: 7, 11, 14, 26, 27, 28), opportunities for more research on the topic of study to deepen existing research or explore more aspects (ID: 1, 2, 4, 12, 13, 17, 18, 19, 20, 22, 23, 24, 29, 30, 32, 33, and 35), and understanding the different abilities in the subjects studied.

\section{Discussion: Complexity, Education 4.0, and Open Innovation}

\subsection{Education 4.0 and Complex Thinking}

As science and technology advance, research studies seem to awaken interest in reasoning for complexity, which will equip current learners to respond to the intellectual challenges ahead. The mapping of relationships among keywords (Figure 3) allowed determining how the critical and creative thinking sub-competencies are forged to build future consolidation of the reasoning for complexity competency in research work and education. Through studying and understanding the thought processes for learning, we construct a foundation for new theories on complexity in education, a latent need according to [12]. Knowing the priority keyword placement of complex and critical thinking in relation to others in research work, we can conceive more sophisticated and comprehensive studies that monitor the interweaving and significance of competencies during problem-solving.

The current decade could see the emergence of educational innovation driven by the study of complex reasoning competency. Although the beginning of the 21st century has shown a relatively low contribution of publications on the topics related to complex thinking, the last three years have shown a more significant trend in the number of publications in either the higher or lower impact factor journals (Figure 4). The interest and awareness in the concept of complex thinking as a competency for educational innovation [5] can be considered one of the causes of the recent increase in publications. Suppose this increase can be considered as a trend. In that case, it allows to further position two aspects of this review: on the one hand, it prevents researchers from taking into account the concept 
of reasoning for complexity in the approach of their research, and on the other hand, it provides a framework on complex thinking to base future work protocols.

The proposed "Reasoning for Complexity in Education 4.0" framework provides avenues that, together with the more typical scenarios investigated with students, enrich the research by integrating quadruple helix stakeholders, industry 4.0 technologies, and access to innovative infrastructure. The most cited articles (Table 3) where complex thinking was a study component focused on student contexts. They included complex thinking in biodiversity, language proficiency, and computer-based mapping of the thinking process. Beyond implementations solely in the educational sector, we must generate initiatives based on collaborative models that integrate industry, government, and civil society [14]. By identifying the topics less explored in the different journals, the possibilities to produce new explorations are broadened in areas that include topics on higher-order thinking, innovative thinking, identity formation, systemic generations, writing culture, and visual thinking, among others.

There is an opportunity to explore the reasoning for complexity as a macro-competency, based on any research method, through combinations of critical thinking with other kinds of thinking. By a wide margin, research studies tend to focus only on critical thinking, mainly through documentary research and qualitative methods (as opposed to mixed and qualitative methods). They pay little attention to including creative, innovative, and systemic types of thinking combined with critical thinking (Figure 5). However, to decode complexity, it is necessary to build systemic frameworks that promote multi-disciplinary research on both topics and researcher profiles $[1,3]$. The starting point to verify the foundation for the study of reasoning for complexity is to document the relationships among the critical focus terms in the research. The next step is to maintain a periodic review of the findings of this study.

We foresee niches for future research and training on the reasoning for complexity regarding Education 4.0 components, mainly in collaborative challenges and knowledge sharing. Among the components of Education 4.0, where research has focused chiefly, are teaching-learning methods and competencies to confront challenges of feasibility, research opportunities, and skills differences (Figure 6). Students trained in reasoning for complexity in such opportunity fields must analyze, synthesize, and solve problems while maintaining an interest in continuous learning [13]. Thus, training students to transform the environment from the perspective of complex reasoning implies a previous recognition of the cognitive competencies necessary to solve problems and integrate scientific, critical, and systemic thinking in the contexts currently faced by citizens.

\subsection{Complex Thinking by Education and Open Innovation}

Open innovation is increasingly gaining momentum. Currently, in the 4th Industrial Revolution, the dynamics of open innovation rises sharply with the explosion of the open innovation paradox, also meaning complexity of open innovation [37,38]. Under such a scenario, there is a growing need to understand the culture, which can control the dynamics of open innovation. In fact, it has been found that the adoption of an open innovation strategy strengthens the propensity to generate eco-innovation [39]. Furthermore, it has also identified the need for organizations that promote a culture of open innovation to adopt a multiculturalist approach at the organizational level, i.e., the acceptance of various types of organizational culture existing in the organization, instead of seeking the alignment of all employees towards a single type of culture [40]. Along with requiring a multiculturalist approach, the topic of open innovation is also greatly influenced by dynamics at the micro and macro levels.

Topics such as the dynamics of open innovation, the micro and macro dynamics of open innovation, and the engineering of open innovation have brought attention to debates around the relationship between sustainability and open innovation [41]. This involves the integration of macro dynamics of open innovation represented by open innovation systems, closed open innovation and social innovation, and micro dynamics of open innovation 
that can be brought together in a quadruple helix model involving industries, universities, governments, and society [42]. In open innovation processes, it is therefore significant that a variety of actors are involved.

From the macrodynamics point of view, open innovation involves a cyclical dynamic between open market innovation, closed open innovation, and social open innovation $[43,44]$. Social open innovation, which was initiated by social entrepreneurs, refers to new creative combinations and connections between technology and society. Social open innovation is becoming the source of market open innovation, which makes entrepreneurs and startups create new combinations and connections between technology and the market [41]. Accordingly, it is important to constantly update the use of technological resources and the pursuit of their integration with society and the market.

Another important aspect to look at regarding open innovation is that of open business models. Saebi et al. considered business model openness from three perspectives: levels of value co-creation, levels of permeability, and levels of collaboration [45]. Levels of value co-creation are the degrees of co-creation necessary for the innovative activities of the firm and value creation. The permeability level signifies the type of knowledge flow between the focal firm and its external knowledge providers. In addition, the level of collaborative capability is the degree to which the firm provides collaboration to govern its interactions with external knowledge providers [46].

\section{Conclusions}

This study focused on analyzing literature on complex thinking linked to Education 4.0 to identify educational practice and research opportunities. Findings include (a) characteristics of studies linking complex thinking, critical thinking, and creative thinking; (b) the qualitative method is predominant in the studies; (c) critical thinking competency has been the most addressed in the research; (d) the predominant components of Education 4.0 are teaching methods and techniques, and (e) the three challenges that stand out for educational research are the project feasibility, research opportunities, and different skills.

Concerning developing reasoning for complexity competencies, Education 4.0 offers a broad opportunity to contribute to educational training practices, from the methodologies to promote competencies (critical, systemic, scientific, and innovative thinking) to the development and implementation of infrastructures that accompany these formative experiences. Likewise, the implications for educational research lie in broadening the forms of study, using quantitative and mixed methods that lead to the deepening of perspectives.

Some limitations of this study lie in limiting the search for articles to just two databases (Scopus and Web of Science), leaving aside other indexing systems that might have publications of value for the study. There remains an opportunity for such an extended analysis and for integrating more linkages with reasoning for complexity. This article aims to be of value to research groups, academicians, and society interested in training opportunities in reasoning for complexity competencies within the framework of Education 4.0.

Author Contributions: Conceptualization, M.S.R.-M.; methodology, M.S.R.-M.; software, I.M.C.-M.; validation, J.S.-Z., M.S.R.-M. and J.M.; formal analysis, J.S.-Z.; investigation, I.M.C.-M.; resources, J.M.; data curation, I.M.C.-M.; writing—original draft preparation, M.S.R.-M.; writing—review and editing, J.S.-Z.; visualization, J.M.; supervision, M.S.R.-M.; project administration, M.S.R.-M.; funding acquisition, M.S.R.-M. All authors have read and agreed to the published version of the manuscript.

Funding: This paper is a product of the project “Open Research Lab: innovation with artificial intelligence and robotics to scale domain levels of reasoning for complexity," with funding from the NOVUS 2021 Fund. The support of Tecnologico de Monterrey for educational innovation projects is appreciated (Agreement: Novus 2021).

Institutional Review Board Statement: Not applicable.

Informed Consent Statement: Not applicable. 
Data Availability Statement: The database with the reviewed articles is hosted in the institutional open repository RITEC with the following link: https:// hdl.handle.net/11285/638752. The reference list of the 35 filtered ID articles is also hosted at RITEC with the following link: https:/ / doi.org/10.5 $281 /$ zenodo. 5746250 .

Acknowledgments: The authors acknowledge the technical support of the Writing Lab, Institute for the Future of Education, Tecnologico de Monterrey, Mexico, in the production of this work.

Conflicts of Interest: The authors declare no conflict of interest.

\section{References}

1. Morin, E. From the concept of system to the paradigm of complexity. J. Soc. Evol. Syst. 1992, 15, 371-385. [CrossRef]

2. Morin, E. Restricted complexity, general complexity. In Science and Us: Philosophy and Complexity. Singapore: World Scientific; 2007; pp. 1-25. Available online: http:/ / www.cogprints.org/5217/1/Morin.pdf (accessed on 15 October 2021).

3. Morin, E. La epistemología de la complejidad. Gaz. Antropol. 2004, 20, 2. Available online: http://hdl.handle.net/10481/7253 (accessed on 25 October 2021). [CrossRef]

4. Mo, J.; Beckett, R.C. Transdisciplinary System of Systems Development in the Trend to X4. 0. In Transdisciplinary Engineering for Complex Socio-Technical Systems-Real-life Applications; IOS Press: Amsterdam, The Netherlands, 2020; pp. 3-12.

5. Miranda, J.; Navarrete, C.; Noguez, J.; Molina-Espinosa, J.-M.; Ramírez-Montoya, M.-S.; Navarro-Tuch, S.A.; Bustamante-Bello, M.-R.; Rosas-Fernández, J.-B.; Molina, A. The core components of education 4.0 in higher education: Three case studies in engineering education. Comput. Electr. Eng. 2021, 93, 107278. [CrossRef]

6. Zadi, I.C.; Montanher, R.C.; Monteiro, A.M. Juego digital para aprender inglés como segunda lengua utilizando el pensamiento complejo. Rev. Científica Gen. José María Córdova 2021, 19, 243-262. [CrossRef]

7. Scipione, L. Philosophy (and argumentation) for children: Some reflection for primary school. Child. Philos. 2020, 16, 1-25. [CrossRef]

8. Deguara, J.; Nutbrown, C. Signs, symbols and schemas: Understanding meaning in a child's drawings. Int. J. Early Years Educ. 2018, 26, 4-23. [CrossRef]

9. Francisco, T.G.; González, J.R.; Morales, W.G. Pedagogía de la Pregunta en la Enseñanza-Aprendizaje del Derecho, como Innovación Metodológica para Desarrollar el Pensamiento Crítico-Complejo: Un Análisis de Caso. Rev. Pedagog. Univ. Didáctica Derecho 2019, 6, 37-58. [CrossRef]

10. Landa, L.G. The systemic logic of return migration in Mexico and its implication for language policy. La lógica sistémica de la migración de retorno en México y su implicación para la política del lenguaje. Rev. Int. Linguist. Iberoam. 2018, 16, 149-160.

11. Hays, J. Wicked Problem: Educating for Complexity and Wisdom. In Wise Management in Organisational Complexity; Palgrave Macmillan: London, UK, 2013; pp. 134-150.

12. Jörg, T.; Davis, B.; Nickmans, G. Towards a new, complexity science of learning and education. Educ. Res. Rev. 2007, 2, 145-156. [CrossRef]

13. Tecnológico de Monterrey. Razonamiento para la complejidad. In Competencias Transversales. Una Visión Desde el Modelo Educativo TEC21. Documento Guía Para el Docente de Educación Superior; Tecnologico de Monterrey: Monterrey, México, $2019 ;$ pp. 62-76.

14. Ramírez-Montoya, M.S.; Álvarez-Icaza, I.; Sanabria-Zepeda, J.C.; Gómez-Zermeño, M.G.; Alemán, L.; López-Caudana, E.O.; Alonso, I.; Miranda, J. Scaling Complex Thinking for Everyone through Open Science: A Conceptual and Methodological Framework. In Proceedings of the 9th International Conference on Technological Ecosystems for Enhancing Multiculturality (TEEM 2021), Barcelona, Spain, 27-29 October 2021.

15. Sellars, M.; Fakirmohammad, R.; Bui, L.; Fishetti, J.; Niyozov, S.; Reynolds, R.; Thapliyal, N.; Liu-Smith, Y.-L.; Ali, N. Conversations on Critical Thinking: Can Critical Thinking Find Its Way Forward as the Skill Set and Mindset of the Century? Educ. Sci. 2018, 8, 205. [CrossRef]

16. Talanquer, V.; Bucat, R.; Tasker, R.; Mahaffy, P.G. Lessons from a Pandemic: Educating for Complexity, Change, Uncertainty, Vulnerability, and Resilience. J. Chem. Educ. 2020, 97, 2696-2700. [CrossRef]

17. Passig, D.; Cohen, L. Measuring the style of innovative thinking among engineering students. Res. Sci. Technol. Educ. 2013, 32, 56-77. [CrossRef]

18. Suryansyah, S.A.; Kastolani, W.; Somantri, L. Scientific thinking skills in solving global warming problems. IOP Conf. Ser. Earth Environ. Sci. 2021, 683, 012025. [CrossRef]

19. Conrad, C.; Serlin, R. The SAGE Handbook for Research in Education: Pursuing Ideas as the Keystone of Exemplary Inquiry. In The SAGE Handbook for Research in Education: Pursuing Ideas as the Keystone of Exemplary Inquiry; SAGE Publications, Inc.: Thousand Oaks, CA, USA, 2011. [CrossRef]

20. Castillo-Martínez, I.M.; Ramírez-Montoya, M.S. Research Competencies to Develop Academic Reading and Writing: A Systematic Literature Review. Front. Educ. 2021, 5, 576961. [CrossRef]

21. Sun, L. Sustainable design: Integrate the creative thinking and innovation into graphical communications. Eng. Des. Graph. J. 2018, 82, 13-28.

22. White, H.A.; Shah, P. Scope of Semantic Activation and Innovative Thinking in College Students with ADHD. Creat. Res. J. 2016, 28, 275-282. [CrossRef] 
23. Lasi, H.; Fettke, P.; Kemper, H.G.; Feld, T.; Hoffmann, M. Industry 4.0. Bus. Inf. Syst. Eng. 2014, 6, 239-242. [CrossRef]

24. Brozzi, R.; Forti, D.; Rauch, E.; Matt, D.T. The Advantages of Industry 4.0 Applications for Sustainability: Results from a Sample of Manufacturing Companies. Sustainability 2020, 12, 3647. [CrossRef]

25. Mourtzis, D.; Vlachou, E.; Dimitrakopoulos, G.; Zogopoulos, V. Cyber-Physical Systems and Education 4.0 -The Teaching Factory 4.0 Concept. Procedia Manuf. 2018, 23, 129-134. [CrossRef]

26. Miranda, J.; Rosas-Fernandez, J.B.; Molina, A. Achieving Innovation and Entrepreneurship by Applying Education 4.0 and Open Innovation. In Proceedings of the 2020 IEEE International Conference on Engineering, Technology and Innovation (ICE/ITMC), New York, NY, USA, 15-17 June 2020; pp. 1-6.

27. Tang, S.; Long, M.; Tong, F.; Wang, Z.; Zhang, H.; Sutton-Jones, K.L. A Comparative Study of Problem-Based Learning and Traditional Approaches in College English Classrooms: Analyzing Pedagogical Behaviors Via Classroom Observation. Behav. Sci. 2020, 10, 105. [CrossRef]

28. Kitchenham, B.; Charters, S. Guidelines for Performing Systematic Literature Reviews in Software Engineering; 2007. Available online: https:/ / www.bibsonomy.org/bibtex/aed0229656ada843d3e3f24e5e5c9eb9 (accessed on 27 October 2021).

29. University of York. (Ed.) Systematic Review; CRD, University of York: York, UK, 2009; Available online: https://bit.ly/2zJzE0E (accessed on 29 October 2021).

30. Verner, J.; Brereton, O.; Kitchenham, B.; Turner, M.; Niazi, M. Systematic literature reviews in global software development: A tertiary study. In Proceedings of the 16th International Conference on Evaluation \& Assessment in Software Engineering (EASE 2012), Ciudad Real, Spain, 14-15 May 2012.

31. Moher, D.; Liberati, A.; Tetzlaff, J.; Altman, D.G.; PRISMA Group. Preferred reporting items for systematic reviews and meta-analyses: The PRISMA statement. BMJ 2009, 339, b2535. [CrossRef]

32. Bauer, M.W.; Gaskell, G. (Eds.) Qualitative Researching with Text, Image and Sound: A Practical Handbook for Social Research; SAGE Publications Ltd.: Thousand Oaks, CA, USA, 2020.

33. Brewerton, P.M.; Millward, L.J. Organizational Research Methods; Sage: London, UK, 2001.

34. Henderikx, M.A.; Kreijns, K.; Kalz, M. Refining success and dropout in massive open online courses based on the intentionbehavior gap. Distance Educ. 2017, 38, 353-368. [CrossRef]

35. Ramírez-Montoya, M.-S.; Lugo-Ocando, J. Systematic review of mixed methods in the framework of educational innovation. Comunicar 2020, 28, 9-20. [CrossRef]

36. Weller, M.; Jordan, K.; Devries, I.; Rolfe, V. Mapping the open education landscape: Citation network analysis of historical open and distance education research. Open Prax. 2018, 10, 109-126. [CrossRef]

37. Lee, M.; Yun, J.J.; Pyka, A.; Won, D.; Kodama, F.; Schiuma, G.; Park, H.; Jeon, J.; Park, K.; Jung, K.; et al. How to Respond to the Fourth Industrial Revolution, or the Second Information Technology Revolution? Dynamic New Combinations between Technology, Market, and Society through Open Innovation. J. Open Innov. Technol. Mark. Complex. 2018, 4, 21. [CrossRef]

38. Yun, J.J.; Won, D.; Park, K. Dynamics from open innovation to evolutionary change. J. Open Innov. Technol. Mark. Complex. 2016, 2, 7. [CrossRef]

39. Pichlak, M.; Szromek, A. Eco-Innovation, Sustainability and Business Model Innovation by Open Innovation Dynamics. J. Open Innov. Technol. Mark. Complex. 2021, 7, 149. [CrossRef]

40. Chandler, N.; Krajcsák, Z. Intrapreneurial Fit and Misfit: Enterprising Behavior, Preferred Organizational and Open Innovation Culture. J. Open Innov. Technol. Mark. Complex. 2021, 7, 61. [CrossRef]

41. Yun, J.J.; Liu, Z. Micro- and Macro-Dynamics of Open Innovation with a Quadruple-Helix Model. Sustainability 2019, 11, 3301. [CrossRef]

42. Cano, J.A.; Londoño-Pineda, A. Scientific Literature Analysis on Sustainability with the Implication of Open Innovation. J. Open Innov. Technol. Mark. Complex. 2020, 6, 162. [CrossRef]

43. Yun, J.J. How do we conquer the growth limits of capitalism? Schumpeterian Dynamics of Open Innovation. J. Open Innov. Technol. Mark. Complex. 2015, 1, 17. [CrossRef]

44. Yun, J.J.; Won, D.; Park, K. Entrepreneurial cyclical dynamics of open innovation. J. Evol. Econ. 2018, 28, 1151-1174. [CrossRef]

45. Saebi, T.; Foss, N.J. Business models for open innovation: Matching heterogeneous open innovation strategies with business model dimensions. Eur. Manag. J. 2015, 33, 201-213. [CrossRef]

46. Tsutsui, Y.; Yamada, N.; Mitake, Y.; Sholihah, M.; Shimomura, Y. A Strategic Design Guideline for Open Business Models. Int. J. Autom. Technol. 2020, 14, 678-689. [CrossRef] 